\title{
Novel Cytopathological Structures Induced by Mixed Infection of Unrelated Plant Viruses
}

\author{
E. M. Martin, J. D. Cho, J. S. Kim, S. C. Goeke, K. S. Kim, and R. C. Gergerich
}

First, fourth, fifth, and sixth authors: Department of Plant Pathology, Plant Science Building 217, University of Arkansas, Fayetteville, AR 72701; second author: Crop Environment and Biotechnology Division, National Crop Experiment Station, R.D.A., Suwon, Korea; and third author: Horticultural Environmental Division, National Horticultural Research Institute, R.D.A., Suwon, Korea.

Accepted for publication 4 September 2003.

\section{ABSTRACT}

Martin, E. M., Cho, J. D., Kim, J. S., Goeke, S. C., Kim, K. S., and Gergerich, R. C. 2004. Novel cytopathological structures induced by mixed infection of unrelated plant viruses. Phytopathology 94:111-119.

\begin{abstract}
When two unrelated plant viruses infect a plant simultaneously, synergistic viral interactions often occur resulting in devastating diseases. This study was initiated to examine ultrastructural virus-virus interactions of mixed viral infections. Mixed infections were induced using potyviruses and viruses from other plant virus families. Novel ultrastructural paracrystalline arrays composed of co-infecting viruses, referred to as mixed virus particle aggregates (MVPAs), were noted in the majority of the mixed infections studied. When the flexuous rod-shaped potyvirus particles involved in MVPAs were sectioned transversely, specific
\end{abstract}

geometrical patterns were noted within some doubly infected cells. Although similar geometrical patterns were associated with MVPAs of various virus combinations, unique characteristics within patterns were consistent in each mixed infection virus pair. Centrally located virus particles within some MVPAs appeared swollen (Southern bean mosaic virus mixed with Blackeye cowpea mosaic virus, Cucumber mosaic virus mixed with Blackeye cowpea mosaic virus, and Sunn hemp mosaic virus mixed with Soybean mosaic virus). This ultrastructural study complements molecular studies of mixed infections of plant viruses by adding the additional dimension of visualizing the interactions between the coinfecting viruses.

Additional keyword: cytopathology.
When two or more viruses infect a plant simultaneously, the outcome, depending upon the combinations, is considered either antagonistic or synergistic (11). Antagonism usually occurs when the co-infecting viruses are related, resulting in interference (24) or cross-protection $(13,16,27)$. Synergism normally occurs in mixed infections when the pair of viruses involved are unrelated, resulting in more severe disease symptoms than those produced by single infections $(1,9,13,14,16,23,26)$.

Many of the severe diseases caused by viral synergistic interactions occur when one of the infecting viruses is a member of the genus Potyvirus. However, not all combinations of unrelated viruses result in increased symptoms (3). The cause of the severe symptom expression and the increase in titer of the non-potyvirus in doubly infected tissue has been reported to be linked to the functional characteristics of the helper component protein of the potyvirus $(17,20,25)$. It has been reported that the potyvirus involved in a synergistic mixed infection induced its own cytopathological inclusions in host cells in addition to those characteristic of each virus (8). A mixed infection of Cowpea mosaic virus (CPMV) or Cowpea severe mosaic virus (CSMV), members of the genus Comovirus, with Bean yellow mosaic virus (BYMV), a member of the genus Potyvirus, in bean induced a striking ultrastructural feature of virus aggregates apparently as a result of the interactions between the two viruses involved in the infection (8). This report described co-infecting viruses arranged in paracrystalline aggregates with CPMV or CSMV icosahedra aligning linearly along the long axis of BYMV rods. When BYMV rods in these mixed virus crystalline aggregates were sectioned transversely, each BYMV rod was surrounded by six equally distanced CPMV or CSMV icosahedra exhibiting a hexagonal arrangement

Corresponding author: E. M. Martin; E-mail address: emartin@uark.edu

Publication no. P-2003-1113-01R

(C) 2004 The American Phytopathological Society
(8). To our knowledge, this was the first report of the occurrence of such a novel paracrystalline structure composed of orderlyarranged virus aggregates in cells of a doubly infected host plant. We refer to these crystallizations of co-infecting virus particles as mixed virus particle aggregates (MVPAs).

In 1994, a severe outbreak of cowpea stunt devastated the cowpea crop in south-central Arkansas (2). This disease, typical for most synergistic viral interactions, is the result of a potyvirus/ non-potyvirus co-infection of Blackeye cowpea mosaic virus (BlCMV) and Cucumber mosaic virus (CMV). This potyvirus/ non-potyvirus combination and other potyvirus/non-potyvirus combinations such as Soybean mosaic virus (SMV) with Bean pod mottle virus (BPMV), which is implicated in the synergistic disease soybean top necrosis $(21,22)$, and the viral combination of Cucumber green mottle mosaic virus (CGMMV) with Watermelon mosaic virus-2 (WMV-2), which causes an economically important disease of watermelon in South Korea (9), were included in this study. The objective of this study was to examine the specific ultrastructural features, particularly the formation of MVPAs, associated with mixed virus infections.

\section{MATERIALS AND METHODS}

Hosts, viruses, and viral combinations. Most viruses used for this research (Table 1) have been studied previously and their single-infection ultrastructural characteristics are well known in their respective hosts. The viral combinations used in this study (Table 2) were potyvirus/non-potyvirus and non-potyvirus/nonpotyvirus combinations, many of which are known to cause synergistic symptom expression in various hosts $(2-4,7,9,14,15$, 19,23,26).

Growing conditions. Seeds were planted in Redi-Earth (Sierra Horticultural Products Co., Marysville, OH) in 250-ml clay pots and grown in a greenhouse maintained at 20 to $24^{\circ} \mathrm{C}$ with supplemental lighting to maintain a minimum photoperiod of $14 \mathrm{~h}$. 
Mechanical inoculation. Seedlings were inoculated at the primary leaf stage ( 7 to 9 days after planting) by dusting Carborundum (silicon carbide powder, grit 600; Buehler, Ltd., Lake Bluff, IL) on the primary leaves and carefully wiping the inoculum on the upper leaf surface. Inoculum was prepared by homogenizing trifoliolate leaves from systemically infected plants in $0.05 \mathrm{M}$ phosphate buffer (PB), pH 7.2. Experimental groups included plants mock-inoculated with $\mathrm{PB}$, plants inoculated with each virus, and plants inoculated with a mixture of two viruses. Inoculum for mixed infections was prepared by obtaining systemically infected trifoliolate leaves from singly infected plants and homogenizing these leaves together.

Electron microscopy. Leaf samples $\left(2 \mathrm{~mm}^{2}\right)$ were taken from trifoliolate leaves of plants 14 days postinoculation and fixed in Karnovsky's fixative for $2 \mathrm{~h}$. Samples were rinsed three times in $0.05 \mathrm{M}$ cacodylate buffer, $\mathrm{pH} 7.2$, post fixed in $1 \%$ osmium tetroxide (buffered in $0.05 \mathrm{M}$ cacodylate buffer, $\mathrm{pH} 7.2$ ), rinsed with distilled water, and en bloc-stained with $0.5 \%$ aqueous uranyl acetate overnight at $4^{\circ} \mathrm{C}$. The tissue was then dehydrated in a graded ethanol series followed by propylene oxide as a transitional fluid and embedded in Spurr's medium. Ultrathin sections were cut with a diamond knife on an MT2B Ultratome (Dupont Company, Newtown, CT). Sections were stained for 4 min with $2 \%$ aqueous uranyl acetate and for 4 min with lead citrate. Grids were observed at $80 \mathrm{kV}$ with a transmission electron microscope (JEM 100 CX; JEOL, Tokyo, Japan).

Serological and ultrastructural verification. Single and mixed virus infections were verified serologically with protein A doubleantibody sandwich enzyme-linked immunosorbent assay (DASELISA) (10) and ultrastructurally by ultrathin sectioning and negative stain electron microscopy.

\section{RESULTS}

DAS-ELISAs verified negative mock-inoculated controls as well as singly and doubly infected plants (data not shown). Of the plants doubly infected with the described viral combinations, macroscopic synergistic symptom expression was noted on the respective hosts. Systemically infected leaf tissue from these plants with severe macroscopic symptoms contained numerous parenchyma cells exhibiting abundant virus particles along with cytopathological inclusions characteristic of each co-infecting

TABLE 1. Virus species and maintenance host species

\begin{tabular}{|c|c|c|}
\hline Virus genus & Virus species ${ }^{\mathrm{a}}$ & Maintenance plant species \\
\hline Comovirus & $\begin{array}{l}\text { Bean pod mottle virus (BPMV) } \\
\text { Cowpea mosaic virus (CPMV) }\end{array}$ & $\begin{array}{l}\text { Glycine max (L.) Merr. cv. Hutcheson } \\
\text { Vigna unguiculata (L.) Walp. cv. Coronet }\end{array}$ \\
\hline Cucumovirus & $\begin{array}{l}\text { Cucumber mosaic virus (CMV) } \\
\text { CMV strain C (CMV-C) }\end{array}$ & $\begin{array}{l}\text { Cucumis sativus L. cv. National Pickling } \\
\text { Cucumis sativus cv. National Pickling }\end{array}$ \\
\hline Potyvirus & $\begin{array}{l}\text { Bean yellow mosaic virus (BYMV) } \\
\text { Blackeye cowpea mosaic virus (BlCMV) } \\
\text { Soybean mosaic virus (SMV-G5) } \\
\text { Watermelon mosaic virus-2 (WMV-2) }\end{array}$ & $\begin{array}{l}\text { Pisum sativum L. cv. Extra Early Alaska } \\
\text { V. unguiculata cv. Coronet } \\
\text { G. max cv. Hutcheson } \\
\text { Cucurbita moschata Poir. cv. Aihobag }\end{array}$ \\
\hline Sobemovirus & $\begin{array}{l}\text { Cowpea strain of Southern bean mosaic virus (CP-SBMV) } \\
\text { Southern bean mosaic virus (SBMV) }\end{array}$ & $\begin{array}{l}\text { V. unguiculata } \mathrm{cv} \text {. Coronet } \\
\text { Phaseolus vulgaris cv. Black Valentine }\end{array}$ \\
\hline Tobamovirus & $\begin{array}{l}\text { Sunn hemp mosaic virus (SHMV) } \\
\text { Cucumber green mottle mosaic virus (CGMMV) }\end{array}$ & $\begin{array}{l}\text { V. unguiculata cv. Coronet } \\
\text { Citrullus vulgaris Schrad cv. Geumno }\end{array}$ \\
\hline
\end{tabular}

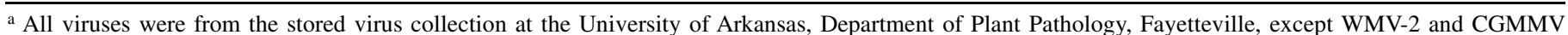
were from the stored virus collection at the School of Agricultural Biotechnology, Seoul National University, Suwon, Korea. BYMV was supplied by M. McLaughlin, U.S. Department of Agriculture-Agricultural Research Service, Crop Science Research Laboratory, Mississippi State, MS.

TABLE 2. Virus combinations and experimental hosts

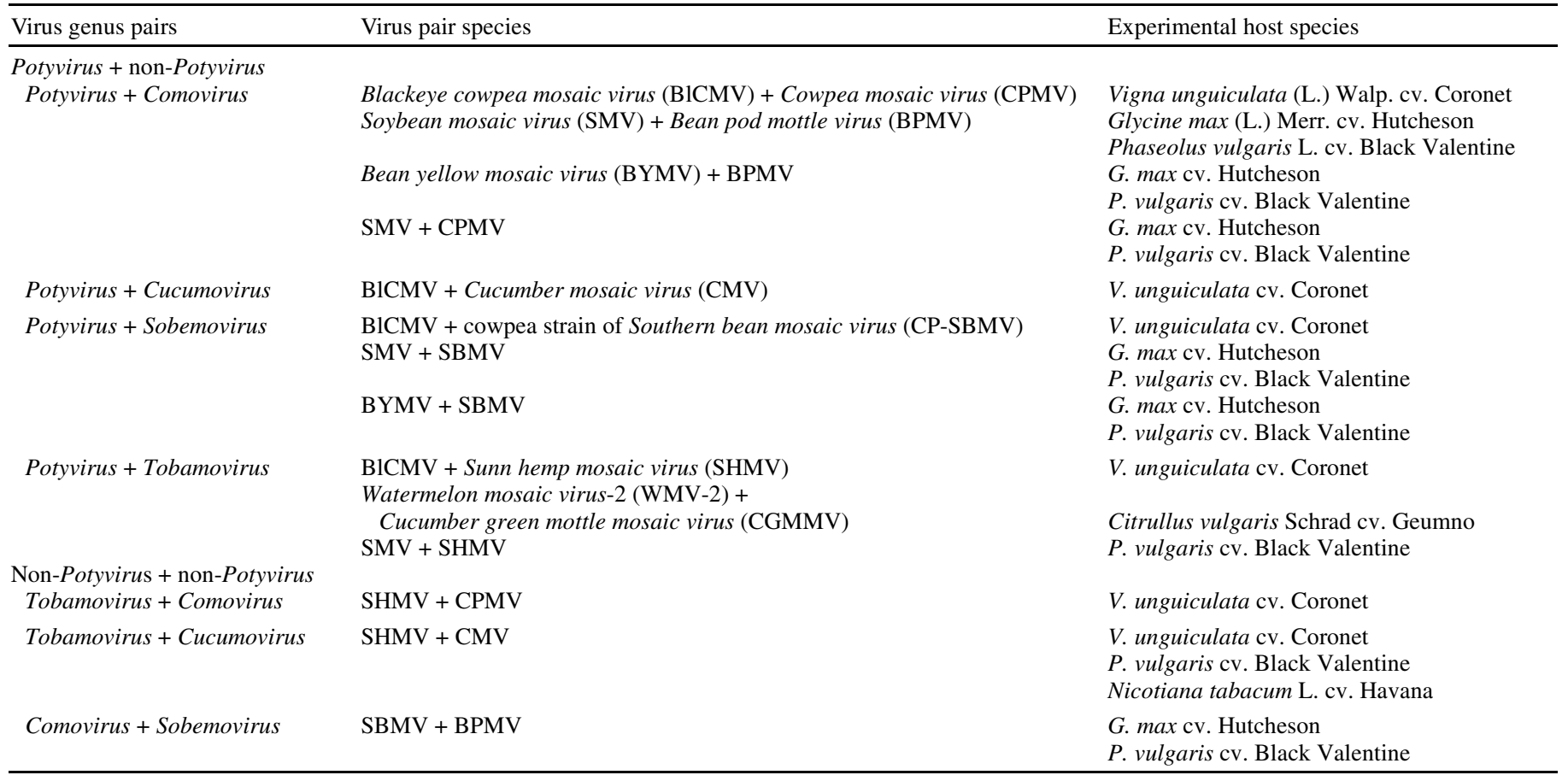


virus, such as various configurations of cylindrical or "pinwheel" inclusions induced by potyviruses (Fig. 1). In addition, some of these cells contained novel cytopathological structures, which we did not observe in cells singly infected with either virus. Paracrystalline virus aggregates composed of both co-infecting virus particles were arranged in specific repeating geometrical patterns, the structure of which depended on the mixed virus combination (Figs. 2 to 5).

In the mixed infection of BlCMV and CMV, eight BlCMV rods in transverse section encircled one CMV icosahedron, exhibiting an octagonal arrangement (Fig. 2A). Similarly, cells doubly infected with BlCMV and cowpea strain of Southern bean mosaic virus (CP-SBMV) contained particles of both viruses and their characteristic cytopathological inclusions, such as vesicular inclusions induced by CP-SBMV (data not shown) and pinwheel inclusions induced by BlCMV (Fig. 1). An octagonal arrangement of co-infecting particles was observed when the BlCMV rods were sectioned transversely. The flexuous rods of BlCMV and the icosahedra of CP-SBMV were aggregated together to form a structure in which a single icosahedron of CP-SBMV was surrounded by eight rods of BlCMV (Fig. 2B).

The mixed infection of two viruses with rod-shaped particles, specifically the flexuous rod-shaped potyvirus WMV-2 and the straight rod-shaped tobamovirus CGMMV, also resulted in the formation of unique geometric particle aggregates. This combination induced a nonagonal MVPA (Fig. 2C) in which a single WMV-2 particle was surrounded by nine evenly spaced CGMMV particles when the rod-shaped particles were sectioned transversely. CGMMV particles were identified by their hollow cores, characteristic of tobamoviruses. MVPAs included WMV-2/CGMMV nonagons and CGMMV paracrystalline arrays intermingled within the nonagons (Fig. 2C). The nonagon crystals and those made with CGMMV particles alone within the large MVPA regions could be easily distinguished based on the particle arrangements and the distances between the particles in the crystals. When the particles of CGMMV crystals and those of nonagons were sectioned transversely, the particles in CGMMV arrays, as distinguished by their hollow cores, were linearly arranged and evenly spaced at a distance of approximately $10 \mathrm{~nm}$, whereas the CGMMV particles in nonagons (CGMMV with WMV-2) were circularly arranged around a centrally located WMV-2 particle and were separated from each other by a slightly greater distance than those in CGMMV crystals (Fig. 2C). In addition, the distance between the central WMV-2 particle and the encircling nine CGMMV particles was approximately $20 \mathrm{~nm}$ (Fig. 2C). The separation distances created an electron-lucent zone within each nonagon between the central WMV-2 particle and encircling nine CGMMV particles. A "fuzzy" electron-dense fibrillar material was observed between the central WMV-2 particle and the nine circularly aligned CGMMV particles.

Although the mixed infections of SMV or BlCMV with SHMV are combinations involving a potyvirus and a tobamovirus, the MVPAs induced by these mixed infections were distinctly different from the MVPAs induced by the WMV-2/CGMMV mixed infection. The mixed infection of SHMV with SMV (Fig. 2D) or BICMV (Fig. 3A) induced nonagonal MVPAs, but in contrast to the WMV-2/CGMMV MVPAs (Fig. 2C), the positions of the virus particles were reversed (Table 3 ); nine potyvirus particles surrounded the central SHMV particle (Figs. 2D and 3A).

MVPAs also were induced with non-potyvirus/non-potyvirus combinations. A mixed infection of the spherical cucumovirus CMV with the rod-shaped tobamovirus SHMV induced a hexagonal MVPA similar to that described in mixed infections of BYMV/CPMV (8). In transverse sections, the straight rod shaped SHMV particles were surrounded by six CMV particles (Fig. 3B).

In addition to the unique particle arrangements apparent in cross sections of MVPAs with rod-shaped particles, longitudinal sec- tions also demonstrated unique arrangements of the co-infecting virus particles. In longitudinal sections of the MVPAs of mixed infections of BICMV with either CMV (Fig. 3C) or CP-SBMV (Fig. 3D), the icosahedral particles were linearly aligned along the long axis of the BlCMV flexuous rods. When the particles of CGMMV and WMV-2 in MVPAs were sectioned longitudinally, the paracrystalline layers usually occurred as a unit of layers, which appeared somewhat "feathery," with irregularly aligned rod-shaped particles perpendicular to an electron-lucent "shaft" (Fig. 4A). Close examination of the particles in these two-stacked layers revealed that the "feathery" appearance was caused by the alignment of the shorter straight rods of CGMMV with longer flexuous rods of WMV-2 (Fig. 4B). Because WMV-2 flexuous rods are approximately twice as long as the CGMMV rods, there was an electron-lucent area close to the middle of these twostacked layers where only the WMV-2 rods were present (Fig. $4 \mathrm{~B})$. The longer WMV-2 flexuous rod linked two CGMMV particles that had aligned along the long axis of the WMV-2 particle (Fig. 4A and B).

When the co-infecting virus particles in the mixed infection of SMV/SHMV were sectioned longitudinally, the paracrystalline layers occurred as a unit of two stacks of SHMV particles with SMV particles spanning across the two stacks (Fig. 4C). The two layers were structurally distinct from those consisting of SHMV alone due to the mixed alignment of the straighter, shorter, and swollen SHMV rods with the longer, thinner, flexuous rods of SMV (Fig. 4C). The swollen SHMV particles appeared as parallelaligned "tubes" with regularly spaced intervals between each particle. These spaced intervals were filled with the thinner, threadlike flexuous rods of SMV (Fig. 4C). An electron-lucent core, a distinguishing characteristic of tobamoviruses, in the middle of each SHMV "tube" was apparent in the longitudinal section of the MVPA (Fig. 4C) and in transverse sections of the MVPA (Fig. 4D, boxed area). At some stages of MVPA formation,

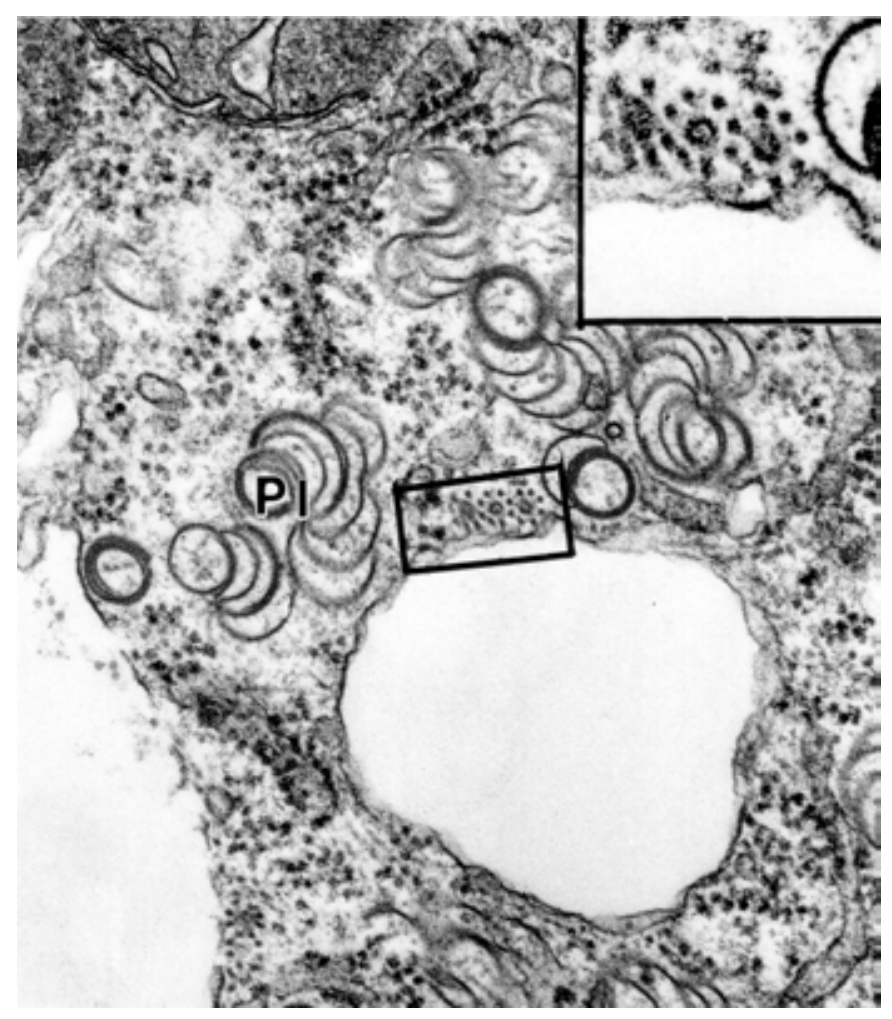

Fig. 1. Transmission electron micrograph of potyvirus-induced pinwheel inclusions (PI), as well as the cowpea strain of Southern bean mosaic virus and Blackeye cowpea mosaic virus induced octagonal mixed virus particle aggregates (boxed area and insert) in doubly infected leaf cells of cv. Coronet cowpea $(\times 40,560$, boxed area $=\times 91,260)$. 
"chains" of endoplasmic reticulum were aligned in the center of the double stacks of the MVPAs (Fig. 4D). The MVPAs without the endoplasmic reticulum association were in close proximity to those with associated endoplasmic reticulum (Fig. 4D).
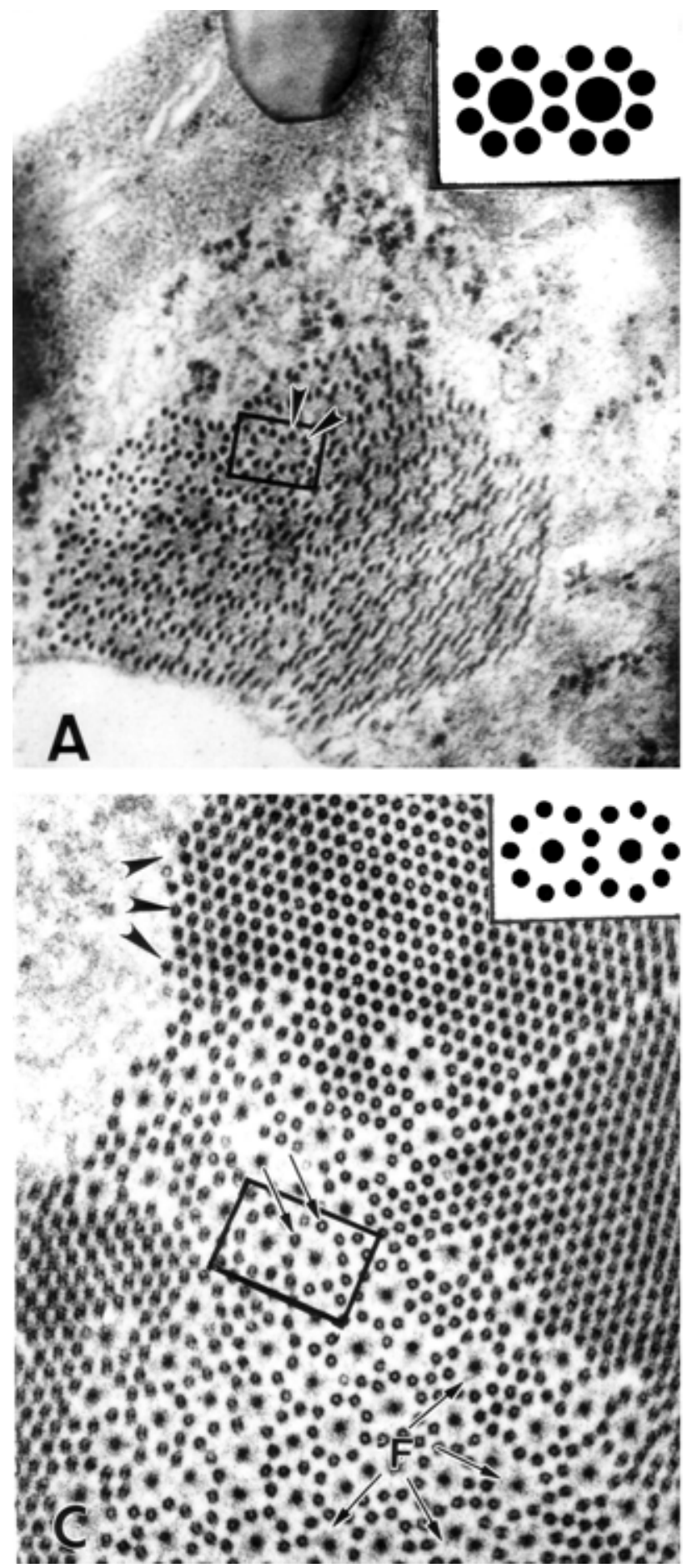

Similar to the SMV/SHMV mixed infection, when MVPAs of the mixed infection of BlCMV/SHMV were sectioned longitudinally through the co-infecting particles, the MVPA arrangement also occurred as double stacks with the tobamovirus straight
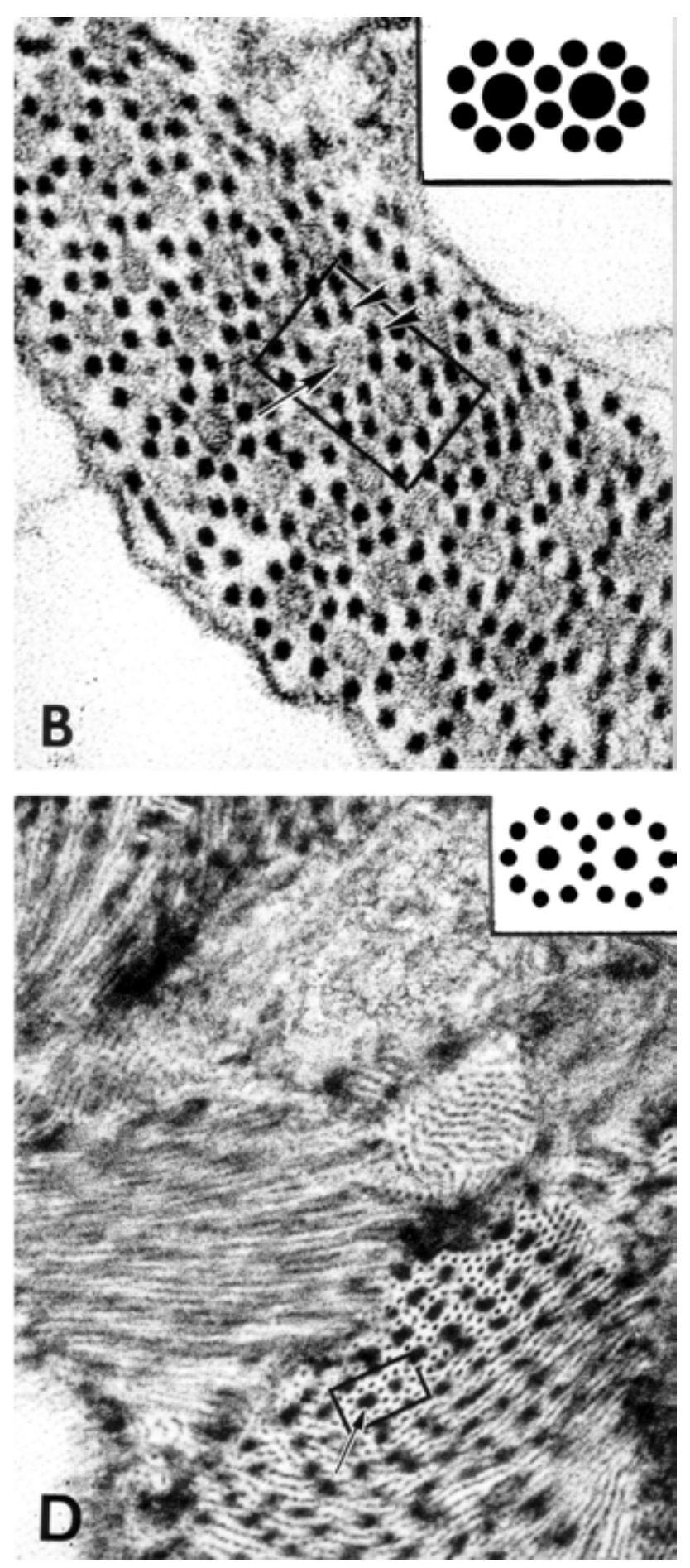

Fig. 2. Transmission electron micrograph of mixed virus particle aggregates (MVPAs). A, MVPA (boxed area) induced by the mixed infection of Cucumber mosaic virus (CMV) and Blackeye cowpea mosaic virus (BlCMV) occurring in doubly infected leaf cells of cv. Coronet cowpea. BlCMV rods (arrowheads) are shown in transverse section. Eight BlCMV rods (sectioned transversely) are evenly spaced encircling a central CMV particle and display an octagonal geometrical pattern. CMV particles appear swollen within the MVPA structure. The swollen CMV particles appear to adjoin the encircling BlCMV particles. The insert illustrates the particle arrangement $(\times 62,400)$. B, Octagonal MVPAs (boxed area) shown in the cowpea strain of Southern bean mosaic virus (CPSBMV) mixed with BlCMV infected leaf cells of cv. Coronet cowpea when the BlCMV rods (arrowheads) were sectioned transversely. The CP-SBMV central particles (arrow) in this octagonal MVPA appear swollen, with a definite "clear zone" between the CP-SBMV spherical central particles and the encircling BlCMV flexuous rods. The insert illustrates the particle arrangement $(\times 136,500)$. C, Paracrystalline arrays of Cucumber green mottle mosaic virus $($ CGMMV) particles in transverse sections (arrowheads) intermingled with MVPA nonagons (arrows) of Watermelon mosaic virus 2 (WMV-2) and CGMMV particles. The paracrystalline structure occupied a large portion of the cytoplasm. $\mathrm{F}=$ fibrillar material. The insert illustrates the particle arrangement $(\times 132,600)$. D, Cross section of Soybean mosaic virus (SMV) and Sunn hemp mosaic virus (SHMV) co-infecting rod-shaped particles revealed a nonagonal MVPA arrangement (boxed area). In contrast to the CGMMV + WMV-2 nonagons, the co-infecting particles were reversed in the mixed infection of SMV + SHMV. Nine SMV particles, evenly spaced, surround the central SHMV particle that appears swollen (arrow) $(\times 70,200)$. 
rods intermingled along the axis of the longer potyvirus flexuous rods (Fig. 5A). The alignment of endoplasmic reticulum "chains" between the double "stacks" of MVPA that was observed in the mixed infection of SHMV/SMV also occurred between the stacks of MVPAs in the BlCMV/SHMV doubly infected cells (Fig. 5B).

In some mixed infection combinations, MVPAs readily formed within leaf cells of doubly infected plants, determined by the ease
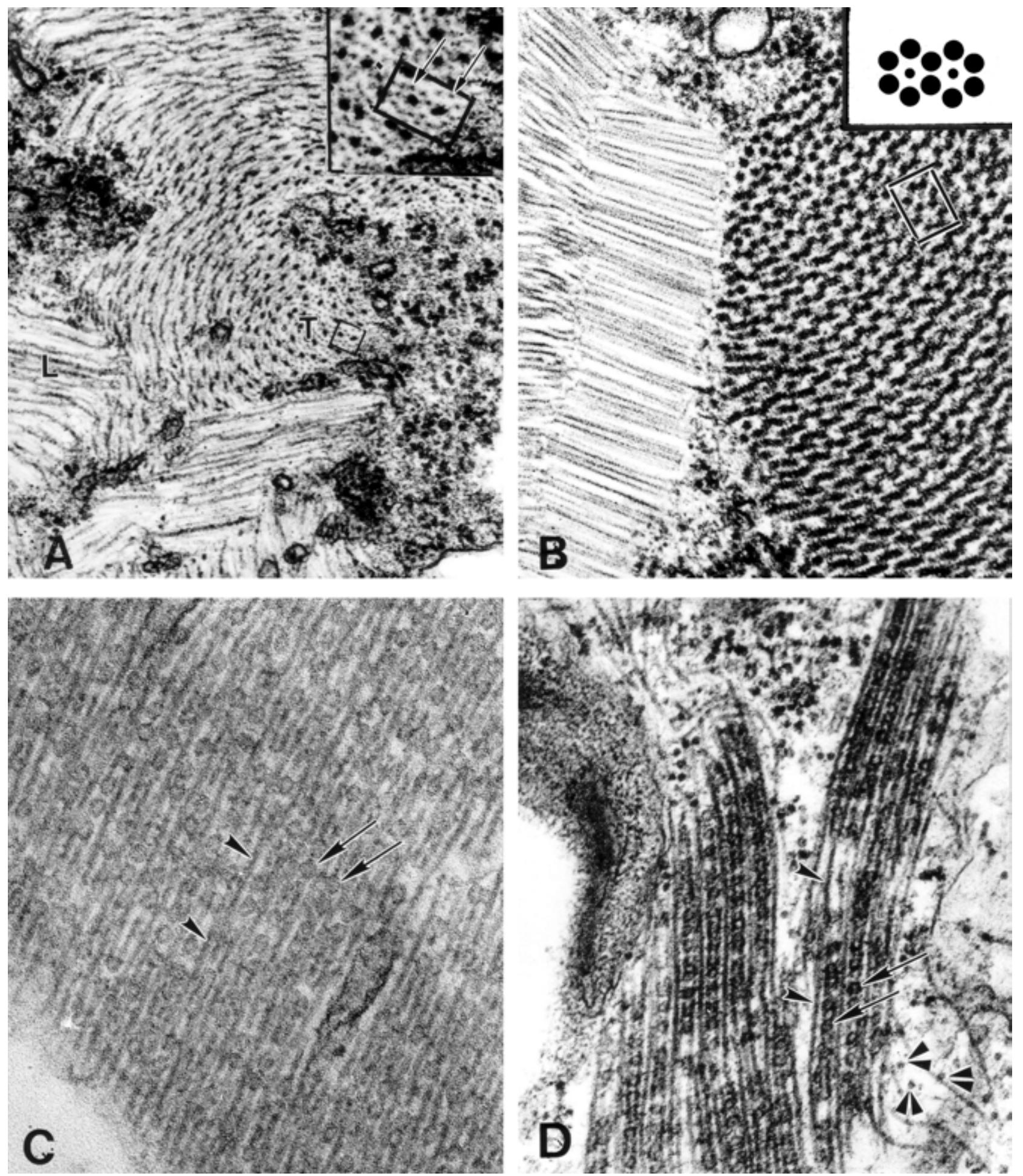

Fig. 3. Transmission electron micrographs of mixed virus particle aggregates (MVPAs). A, Transverse (T) and longitudinal (L) sections through Blackeye cowpea mosaic virus (BlCMV) + Sunn hemp mosaic virus (SHMV) induced nonagonal MVPAs (MV). Nine BlCMV particles encircle the central SHMV core particle. The BlCMV particles (arrows in insert) do not appear as evenly spaced around the central SHMV particles as was observed in other potyvirus/ tobamovirus MVPAs studied. (Compare this insert with the boxed area in Figure 2D). Although the central SHMV particles appear swollen, they are not as swollen as the SHMV particles in the Soybean mosaic virus $($ SMV) + SHMV induced MVPAs $(\times 40,560$, boxed area $=\times 81,120)$. B, Hexagonal MVPA composed of a central SHMV particle encircled by six Cucumber mosaic virus (CMV) spherical particles (boxed area). The insert illustrates the particle arrangement. This was a mixed infection involving two unrelated non-potyviruses $(\times 90,000)$. C, Longitudinal sections of BlCMV flexuous rods (arrowheads) with CMV spherical particles (arrows) aligning the long axis of the BlCMV particles in doubly infected leaf cells of cv. Coronet cowpea. CMV particles appear swollen in this longitudinal section $(\times 78,000)$. D, Longitudinal sections through the BlCMV rods (arrowheads) with cowpea strain of Southern bean mosaic virus (CP-SBMV) spherical particles (arrows) aligning the BlCMV axis in cells doubly infected with CP-SBMV and BlCMV. CP-SBMV particles associated with MVPAs appear swollen (arrows). CP-SBMV particles not associated with MVPAs do not appear swollen (double arrowheads, lower right corner) ( $\times 60,840$ ). 
of locating MVPAs in ultrathin sections. In other mixed infections, MVPAs were more difficult to locate, as was the case with mixed infections of CMV/BICMV, CP-SBMV/BICMV, CGMMV/ WMV-2, SMV/SHMV, and BlCMV/SHMV. MVPAs apparently occurred less frequently in other mixed infections such as the combination of CMV and SHMV (Fig. 3B). Although macroscopic synergistic symptoms were apparent in cv. Black Valentine bean or cv. Hutcheson soybean plants in mixed infections of SMV and BPMV, and abundant virus particles of both viruses were noted in leaf cells, no MVPAs were observed.
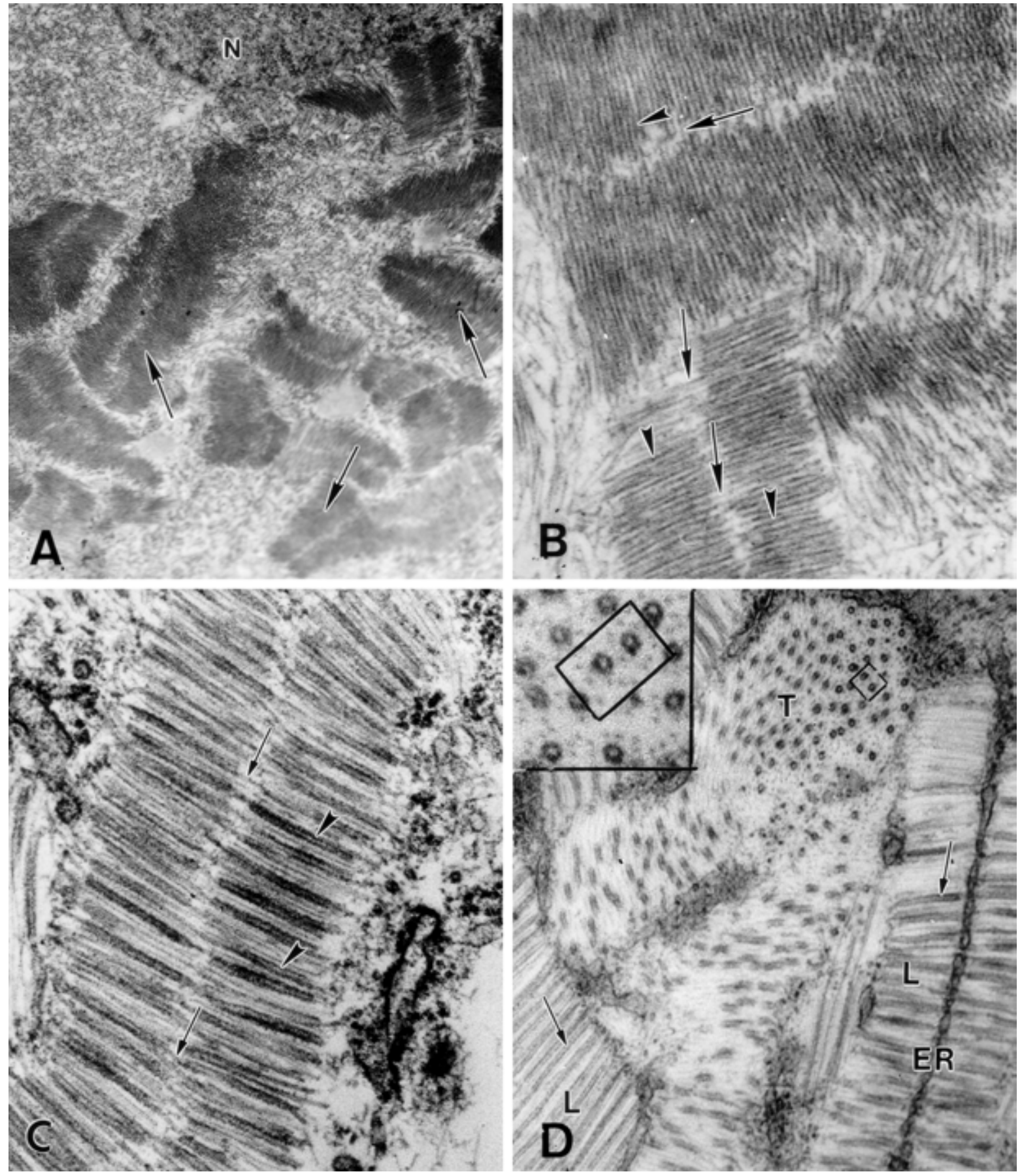

Fig. 4. Transmission electron micrographs show longitudinal and transverse sections through mixed virus particle aggregates (MVPAs). A, Low magnification of Watermelon mosaic virus-2 (WMV-2) + Cucumber green mottle mosaic virus (CGMMV) doubly infected leaf cell showing abundant virus particles in MVPAs (arrows) that appear "feathery". Nucleus $=\mathrm{N}(\times 27,300)$. B, Longitudinal section through the MVPA nonagons showing flexuous rod-shaped WMV-2 particles (arrows) within the central area of the "feathery" longitudinal section through the MVPAs. The CGMMV particles (arrowheads) aligned the WMV-2 flexuous rod-shaped particles in an irregular fashion but do not occupy the central region of the flexuous rods, thereby giving a "feathery" appearance to the structure $(\times 56,400)$. C, Longitudinal sections through the MVPAs formed by Sunn hemp mosaic virus (SHMV) and Soybean mosaic virus (SMV). The double stacked SHMV straight rods were linked by the longer SMV flexuous rods. SMV flexuous rods are more than twice the length of the SHMV rods. Due to the longer SMV rods, there is an electron-lucent region spanning the middle between the double stacks that is occupied by the midsection of SMV rods (arrows). SHMV particles (obvious by their hollow central cores - arrowheads) are apparently swollen when associated in this MVPA ( $\times 40,560)$. D, Transverse (T) and longitudinal (L) sections through the MVPAs formed by SHMV and SMV, indicating a complex alignment of co-infecting particles. The central core of the SHMV swollen particles is obvious not only in the cross section of the particles (insert), but also in longitudinal sections showing an electron-lucent area throughout the length of the SHMV particles (arrows). One stack of MVPAs, sectioned longitudinally, was associated with "chains" of endoplasmic reticulum (ER) aligning the central region of the stack. The other MVPA stack, located at the bottom left of the micrograph, did not have associated endoplasmic reticulum in this plane of sectioning $(\times 31,200$; boxed area $=\times 78,000)$. 
Along with differences in particle arrangement of the various mixed infection combinations (Table 3), considerable change in particle dimensions occurred in the central particle of the MVPAs of some mixed infections. In transverse sections through BlCMV/ CMV MVPAs, the spherical particles of CMV appeared swollen to approximately twice their normal size when compared with CMV particles occurring freely in the cytoplasm of the doubly infected cells. No morphological differences of BlCMV rods between those associated with octagons (Fig. 2A) and those not associated with octagons (data not shown) were noted.

Similar to the CMV particles within the BlCMV/CMV MVPAs, the spherical central CP-SBMV particles within the octagonal BlCMV/CP-SBMV MVPAs also appeared swollen (Fig. 2B). CPSBMV particles centrally located in the MVPAs of the mixed infection of CP-SBMV/BICMV were swollen to approximately 40 nm. However, unlike the octagons formed in the BlCMV/ CMV MVPAs (Fig. 2A), the eight BlCMV particles encircling a single CP-SBMV particle were not physically adjoined to the surface of the CP-SBMV particle, but appeared to be at a shorter equal distance from the CP-SBMV particle (Fig. 2B). This distance formed an electron-lucent "halo" around the CP-SBMV particle (Fig. 2B). At times, fibrils were discernible in the halo between the centrally located CP-SBMV and the surrounding eight BlCMV particles (Fig. 2B). CP-SBMV particles not associated with the MVPAs did not appear swollen (Fig. 3D).

In the transverse section of the SMV/SHMV MVPA (Fig. 4D), the centrally located SHMV particles in each MVPA nonagon were approximately $39 \mathrm{~nm}$ in diameter compared with $18 \mathrm{~nm}$ in diameter for SHMV particles in singly infected cells or those not associated with nonagons in doubly infected cells. Although the central SHMV particle was swollen, the electron-lucent central core surrounded by the electron-dense wall, characteristic of transverse sections through tobamovirus particles, was still obvious (Fig. 4D). In the BlCMV/SHMV MVPA, the central SHMV particles in the nonagonal MVPAs appeared somewhat swollen, but not to the extent observed in the SMV/SHMV MVPAs.

\section{DISCUSSION}

Specific geometrical MVPA patterns occurred consistently with the various mixed viral combinations when the rod-shaped particles were sectioned transversely (Table 3 ). In transverse sections through the rod-shaped particles, octagonal (1:8 particle ratio) or hexagonal (1:6 particle ratio) MVPAs occurred when one of the infecting viruses was a spherical particle and the other was either a straight rod (CMV/SHMV) or a flexuous rod-shaped particle (BlCMV/CMV or BlCMV/CP-SBMV). This occurred not only with mixtures involving potyvirus/non-potyvirus combinations but also with non-potyvirus/non-potyvirus combinations as noted with CMV/SHMV infection. Nonagon (1:9 particle ratio) arrangements were only observed in mixed infections of rod-shaped viruses such as potyviruses mixed with tobamoviruses (WMV-2/ CGMMV, SMV/SHMV, and BlCMV/SHMV). There may be specific interactions between the coat proteins of the co-infecting viruses that determine whether virus particles interact, and spatial constraints that define the geometric arrangements of interacting particles. Interestingly, the central particle in the potyvirus/tobamovirus MVPAs differed depending on the specific viruses in the mixed infection. The potyvirus was centrally located in the WMV-2/CGMMV MVPA, whereas the tobamovirus was centrally located in the SMV/SHMV and BlCMV/SHMV MVPAs.

Not only were differences in virus arrangements noted in transverse sections of the MVPAs, but also in longitudinal sections of MVPAs with rod-shaped particles. This was particularly obvious when straight rod-shaped particles (tobamovirus) were mixed with flexuous rod-shaped particles (potyvirus). In the WMV-2/ CGMMV MVPAs, the particle arrangement appeared feathery in longitudinal sections due to the staggered alignment of the shorter straight rods of CGMMV intermingled with the longer flexuous rods of WMV-2. In contrast, virus particle arrangements did not appear "feathery" in other potyvirus/tobamovirus mixed infections such as BlCMV/SHMV and SMV/SHMV, but rather these viruses appeared more evenly stacked with the shorter tobamovirus
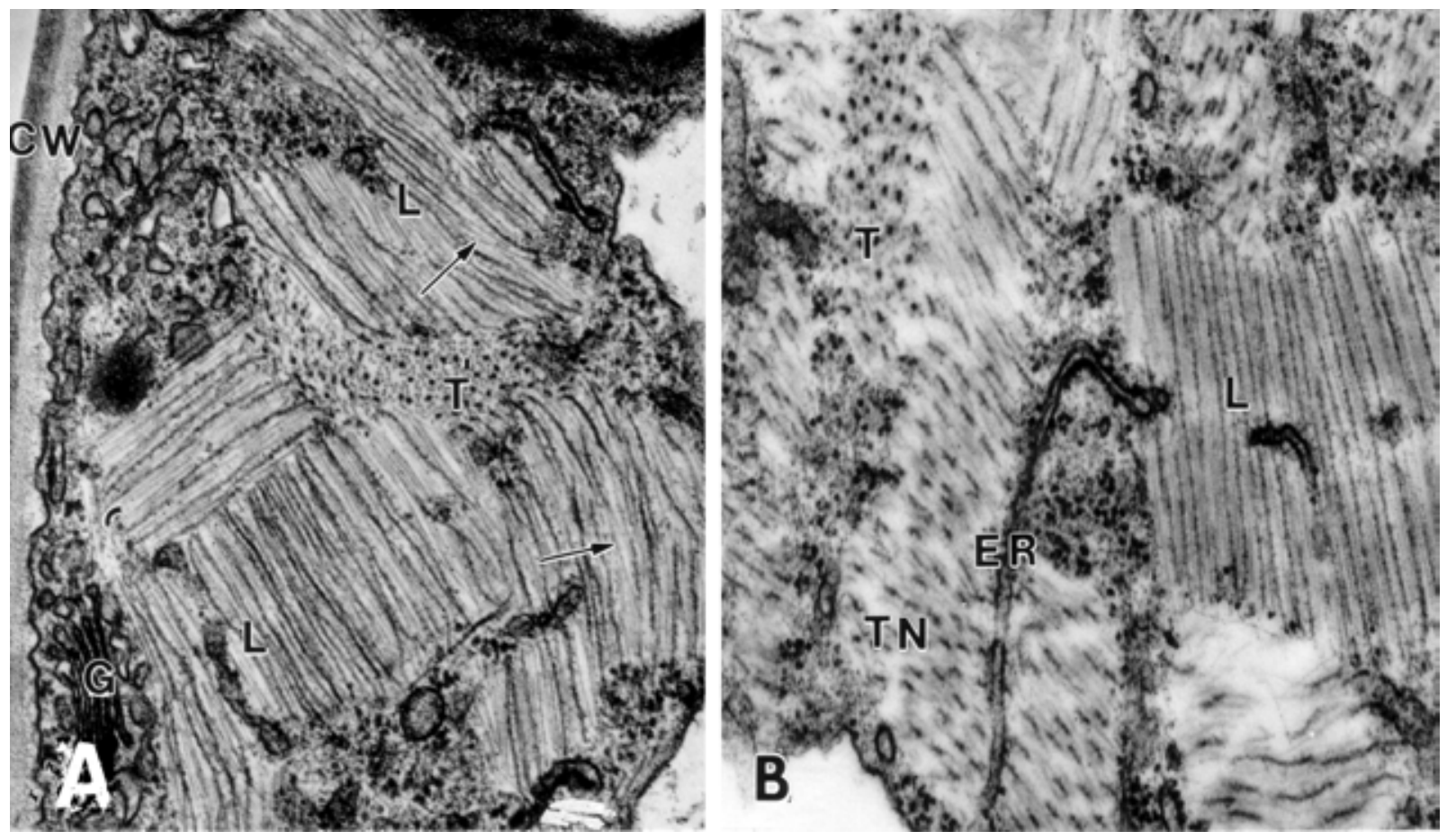

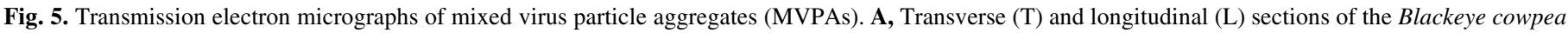

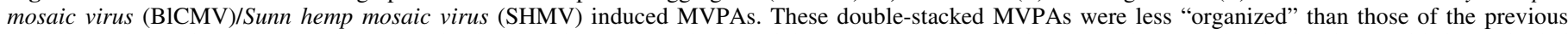

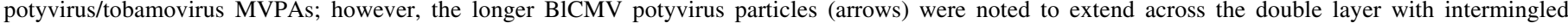

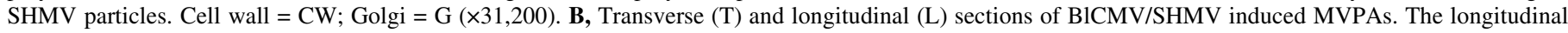

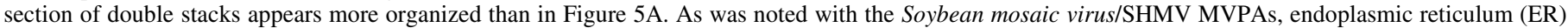
was associated with the BlCMV/SHMV MVPAs, as noted in longitudinal as well as tangential (TN) sections of the MVPAs ( $\times 31,200)$. 
particles aligning evenly on either end of the longer potyvirus particles (Figs. 4C and 5A). As with the transverse sections through the MVPAs, the particle arrangement in the longitudinal sections is assumed to be a reflection of specific protein-protein interactions between the coat proteins of the co-infecting viruses.

Protein-protein interactions not only influenced the arrangement of virus particles within the virus aggregates, but also apparently caused a change in virus particle dimension. In the WMV-2/CGMMV MVPA, there was a single, distinct central particle of WMV-2 encircled by nine CGMMV particles, thereby giving a "crisp" appearance. The "fuzzy" appearance of the SHMV/ SMV MVPA nonagon was due to the swelling of the SHMV particle in response to the MVPA association. It has been shown that particles of SBMV swell when the virus is subjected, in vitro, to extreme conditions of high $\mathrm{pH}(\mathrm{pH} 8.25)$ and the lack of $\mathrm{Ca}^{2+}$ (6). It was suggested that the swelling of SBMV particles was necessary for initiation of virus-directed protein synthesis in vitro and that the cause of swelling was due to the removal (or breaking) of the protein-protein bonds of the viral capsid leaving only the protein-RNA bonds available for particle stabilization (6). Other viruses, such as Alfalfa mosaic virus, are stabilized by protein-RNA bonds and are considered permanently swollen $(12,18)$. Normally, SBMV particles are approximately $30 \mathrm{~nm}$ in diameter; however, with removal of calcium at a high $\mathrm{pH}$ of 8.25 , the particles swell to approximately $44 \mathrm{~nm}$ (5). The swelling of the CP-SBMV particles centrally located in the MVPAs of the mixed infection of CP-SBMV/BICMV may be a result of stress on the protein-protein bonds in the CP-SBMV particle exerted by the BlCMV particle in the MVPA formation. Similarly, swelling of the CMV and SHMV particles within the MVPA in the mixed infections of CMV/BICMV and SHMV/SMV, respectively, are possibly induced by stress to the protein-protein bonds. We believe that the MVPAs described in this study are composed of the co-infected virus particles based on (i) ELISA results that demonstrate the presence of each co-infected virus in the individual plants used for electron microscopy studies, (ii) the distinct morphological characteristics of virus particles in MVPAs as well as virus particles not associated with MVPAs, and (iii) the presence of viroplasmic inclusions typically found in single infections of the viruses used in these studies. Immunogold labeling studies to identify virus particles within the MVPAs were not successful, perhaps because the antigenic sites on the virus particles are masked by the interaction with the other virus particle.

This ultrastructural study complements molecular studies of plant virus mixed infections $(20,25)$ by visualizing the interactions between particles of the co-infecting viruses. The most striking aspect was the occurrence of novel MVPAs, a crystallization of co-infecting virus particles, that was distinct for each virus combination. MVPA formation is apparently due to interactions between the coat proteins of the co-infecting viruses. Viral crystalline arrays are known to occur in plant cells singly infected and depend on viral properties and not viral concentrations (11). This study is a continuation of a previous study (8) and expands our knowledge of the formation of crystalline arrays composed of viruses co-infecting the same cell. Crystallization of plant viruses occurs in single infections within infected cells, and some viruses such as Turnip yellow mosaic virus readily crystallize in vitro (11). It is not known whether MVPAs form in vitro when suspen-

TABLE 3. Mixed virus particle aggregates occurring within host cells

\begin{tabular}{|c|c|c|c|}
\hline Virus combinations & Virus pairs ${ }^{\mathrm{a}}$ & Particle ratio & Virus aggregate structure \\
\hline \multicolumn{4}{|l|}{ Potyvirus + non-Potyvirus } \\
\hline Potyvirus + Comovirus ${ }^{\mathrm{b}}$ & $\begin{array}{l}\text { Bean yellow mosaic virus (BYMV)* }+ \\
\text { Cowpea mosaic virus (CPMV) Carr and Kim (8) }\end{array}$ & $1: 6$ & \\
\hline Potyvirus + Cucumovirus ${ }^{\mathrm{c}}$ & $\begin{array}{l}\text { Blackeye cowpea mosaic virus }(\mathrm{BlCMV})+ \\
\text { Cucumber mosaic virus }(\mathrm{CMV})^{*}\end{array}$ & $1: 8$ & \\
\hline Potyvirus + Sobemovirus ${ }^{\mathrm{c}}$ & $\begin{array}{l}\text { BlCMV + cowpea strain of Southern bean } \\
\text { mosaic virus }(\mathrm{CP}-\mathrm{SBMV})^{*}\end{array}$ & $1: 8$ & \\
\hline Potyvirus + Tobamovirus ${ }^{\mathrm{d}}$ & $\mathrm{BlCMV}+$ Sunn hemp mosaic virus (SHMV)* & $1: 9$ & \\
\hline Potyvirus + Tobamovirus ${ }^{\mathrm{d}}$ & Soybean mosaic virus $(\mathrm{SMV})+\mathrm{SHMV} *$ & $1: 9$ & \\
\hline Potyvirus + Tobamovirus ${ }^{\mathrm{e}}$ & $\begin{array}{l}\text { Watermelon mosaic virus-2 (WMV-2)* }+ \\
\text { Cucumber green mottle mosaic virus (CGMMV) }\end{array}$ & $1: 9$ & \\
\hline \multicolumn{4}{|l|}{ Non-Potyvirus + non-Potyvirus } \\
\hline Tobamovirus + Cucumovirus ${ }^{\mathrm{f}}$ & $\mathrm{SHMV}^{*}+\mathrm{CMV}$ & $1: 6$ & \\
\hline
\end{tabular}

a An asterisk indicates the central particle in the virus aggregate.

b In cv. Cherokee wax bean.

c In cv. Coronet cowpea.

${ }^{\mathrm{d}}$ In cv. Black Valentine bean.

e In cv. Geumno watermelon.

f In cv. Havana tobacco. 
sions of purified viruses are mixed together under conditions conducive to MVPA formation. In vitro crystallization studies with the virus pairs used in this study would add to the understanding of virus-virus interactions in mixed plant virus infections and also provide a model system to study the effect of crystallization on the integrity and infectivity of the viruses that form MVPAs in vivo.

\section{ACKNOWLEDGMENTS}

Published with the approval of the Director of the Arkansas Agricultural Experiment Station.

\section{LITERATURE CITED}

1. Ahn, K. K., Kim, K. S., Gergerich, R. C., and Jensen, S. G. 1998. High plains disease of corn and wheat: Ultrastructural and serological aspects. J. Submicrosc. Cytol. Pathol. 30:563-571.

2. Anderson, E. J., Kline, A. S., Kim, K. S., Goeke, S. C., and Albritton, C. W. 1994. Identification of cowpea stunt disease in south central Arkansas. Ark. Farm Res. 43:14-15.

3. Anjos, J. R., Jarlfors, U., and Ghabrial, S. A. 1992. Soybean mosaic potyvirus enhances the titer of two comoviruses in dually infected soybean plants. Phytopathology 82:1022-1027.

4. Barker, H. 1987. Invasion of non-phloem tissue in Nicotiana clevelandii by potato leaf roll luteovirus is enhanced in plants also infected with potato Y potyvirus. J. Gen. Virol. 68:1223-1227.

5. Brisco, M., Haniff, C., Hull, R., Wilson, T. M. A., and Sattelle, D. B. 1986. The kinetics of swelling of southern bean mosaic virus: A study using photon correlation spectroscopy. Virology 148:218-220.

6. Brisco, M., Hull, R., and Wilson, T. M. A. 1986. Swelling of isometric and of bacilliform plant virus nucleocapsids is required for virus-specific protein synthesis in vitro. Virology 148:210-217.

7. Calvert, L. A., and Ghabrial, S. A. 1983. Enhancement by soybean mosaic virus of bean pod mottle virus titer in doubly infected soybean. Phytopathology 73:992-997.

8. Carr, R. J., and Kim, K. S. 1983. Ultrastructure of mixed plant virus infection: Bean yellow mosaic virus with cowpea severe mosaic virus or cowpea mosaic virus in bean. Virology 124:338-348.

9. Cho, J. D., Kim, J. S., Choi, H. S., La, Y. J., and Kim, K. S. 2000. Ultrastructural aspects of the mixed infections of watermelon mosaic potyvirus isolated from pumpkin and cucumber green mottle mosaic tobamovirus from watermelon. Plant Pathol. J. 16:216-221.

10. Edwards, M. L., and Cooper, J. I. 1985. Plant virus detection using a new form of indirect ELISA. J. Virol. Methods 11:309-319.
11. Hull, R. 2002. Matthews' Plant Virology. 4th ed. Academic Press, San Diego, CA.

12. Hull, R., Hills, G. J., and Markham, R. 1969. Studies on alfalfa mosaic virus. II. The structure of the virus components. Virology 37:416-428.

13. Hull, R., and Plaskitt, A. 1970. Electron microscopy on the behavior of two strains of alfalfa mosaic virus in mixed infections. Virology 42:773776.

14. Jensen, S. G., Lane, L. C., and Seifers, D. L. 1996. A new disease of maize and wheat in the high plains. Plant Dis. 80:1387-1390.

15. Karyeija, R. F., Kreuze, J. F., Gibson, R. W., and Valkonen, J. P. T. 2000. Synergistic interactions of a potyvirus and a phloem-limited crinivirus in sweet potato plants. Virology 269:26-36.

16. Khan, J. A., Lohuis, H., Goldbach, R. W., and Dijkstra, J. 1994. Distribution and localization of bean common mosaic virus and bean black root virus in stems of doubly infected bean plants. Arch. Virol. 138:95-104.

17. Maia, I. G., Haenni, A. L., and Bernardi, F. 1996. Potyviral HC-Pro: A multifunctional protein. J. Gen. Virol. 77:1335-1341.

18. Oostergetel, G. T., Krijgsman, P. C. J., Mellema, J. E., Cusack, S., and Miller, A. 1981. Evidence for the absence of swelling of alfalfa mosaic virions. Virology 109:206-210.

19. Pio-Ribeiro, G., Wyatt, S. D., and Kuhn, C. W. 1978. Cowpea stunt: A disease caused by a synergistic interaction of two viruses. Phytopathology 68:1260-1265.

20. Pruss, G., Ge, X., Shi, X. M., Carrington, J. C., and Vance, V. B. 1997. Plant viral synergism: The potyviral genome encodes a broad-range pathogenicity enhancer that transactivates replication of heterologous viruses. Plant Cell 9:859-868.

21. Ross, J. P. 1963. Interaction of the soybean mosaic and bean pod mottle viruses infecting soybean. (Abstr.) Phytopathology 53:887.

22. Ross, J. P. 1968. Effects of single and double infections of soybean mosaic and bean pod mottle viruses on soybean yield and seed characters. Plant Dis. Rep. 52:344-348.

23. Sackey, S. T., and Francki, R. I. B. 1990. Interaction of cucumoviruses in plants: Persistence of mixed infections of cucumber mosaic and tomato aspermy virus. Physiol. Mol. Plant Pathol. 36:409-419.

24. Sakai, F., Dawson, J. R. O., and Watts, J. W. 1983. Interference in infections of tobacco protoplasts with two bromoviruses. J. Gen. Virol. 64:1347-1354

25. Vance, V. B., Berger, P. H., Carrington, J. C., Hunt, A. G., and Shi, X. M. 1995. 5'-Proximal potyviral sequences mediate potato virus X/potyviral synergistic disease in transgenic tobacco. Virology 206:583-590.

26. Walkey, D. G. A., and Payne, C. J. 1990. The reaction of two lettuce cultivars to mixed infection by beet western yellows virus, lettuce mosaic virus and cucumber mosaic virus. Plant Pathol. 39:156-160.

27. Watts, J. W., and Dawson, J. R. O. 1980. Double infection of tobacco protoplasts with brome mosaic virus and cowpea chlorotic mottle virus. Virology 105:501-507. 